\title{
Perbandingan Prediksi Tinggi Muka Air Bendungan Wonogiri dengan Single Exponential Smoothing dan Brown's Exponential Smoothing
}

\author{
Retno Tri Vulandari' ${ }^{1}$, Dwi Remawati ${ }^{2}$, Yustina Retno $W^{3}$, Hendro \\ Wijayanto ${ }^{4}$, Wawan Laksito YS
}

Teknik Informatika, STMIK Sinar Nusantara, Surakarta; vulandari.sinus@gmail.com

\begin{abstract}
Abstrak
Intensitas hujan tahunan di daerah aliran sungai (DAS) Bengawan Solo mengakibatkan debit aliran sungai besar di beberapa anak sungai. Debit aliran sungai yang besar mengakibatkan tinggi muka air di beberapa pos pemantauan meningkat. Tinggi muka air di setiap pos pemantauan diukur setiap hari dengan periode yang sama, pagi (06.00), siang (12.00), dan sore (18.00). oleh karena itu data tinggi muka air merupakan data runtun waktu. Salah satu metode peramalan data runtun waktu adalah single exponential smoothing dan Brown's double exponential smoothing. Dalam penelitian ini akan dilakukan pemodelan data tinggi muka air sungai Bengawan Solo pada pos pemantauan Wonogiri Juni - Desember 2018.
\end{abstract}

Kata Kunci. Analisa Runtun Waktu, Exponential Smoothing

\begin{abstract}
The annual rainfall intensity in the Bengawan Solo watershed results in large river flow discharge in several tributaries. The large flow of the river flow has increased the water level in some monitoring posts. The water level in each monitoring post is measured every day with the same period, morning (06.00), afternoon (12.00), and afternoon (18.00). Therefore water level data is time series data. One time data forecasting method is single exponential smoothing and Brown's double exponential smoothing. In this research, modeling of Bengawan Solo River water level data on the Wonogiri monitoring post, June - December 2018.
\end{abstract}

Keywords. Time Series Analysis, Exponential Smoothing

\section{Pendahuluan}

Data debit atau aliran sungai merupakan informasi yang paling penting bagi pengelola sumber daya air. Debit puncak (banjir) diperlukan untuk merancang bangunan pengendali banjir. Sementara data debit aliran kecil diperlukan untuk perencanaan alokasi air untuk berbagai macam keperluan, 
terutama pada musim kemarau panjang. Debit aliran rata-rata tahunan dapat memberikan gambaran potensi sumber daya air yang dapat dimanfaatkan dari suatu daerah aliran sungai. Debit adalah laju aliran air yang melewati suatu penampang melintang sungai per satuan waktu. Dalam laporanlaporan teknis, debit aliran biasanya ditunjukkan dalam bentuk hidrograf aliran. Hidrograf aliran adalah suatu perilaku debit sebagai respon adanya perubahan karakteristik biogeofisik yang terjadi karena kegiatan pengelolaan DAS dan adanya fluktuasi musiman atau tahunan seperti perubahan iklim lokal (Mahmuda, 2012).

Intensitas hujan tahunan di daerah aliran sungai (DAS) Bengawan Solo mengakibatkan debit aliran sungai besar di beberapa anak sungai. Debit aliran sungai yang besar mengakibatkan tinggi muka air di beberapa pos bendungan meningkat. Pengukuran tinggi muka air pada tiap bendungan. Hal ini dibutuhkan untuk mengantisipasi banjir. Penelitian ini bertujuan untuk melakukan upaya peringatan dini banjir dengan analisa tinggi muka air pada tiap bendungan daerah aliran sungai Bengawan Solo wilayah Hulu. Tinggi muka air merupakan data runtun waktu.

\section{Metode Penelitian}

\subsection{Data Runtun Waktu (Time Series)}

Peramalan didasarkan pada data historis atau data runtut waktu sehinga memperoleh nilai dugaan dari suatu periode tertentu.Runtut waktu (time series) adalah hasil pengamatan kontinyu atau data yang disusun berdasarkan urutan waktu (Boedijoewono, 2016) Sebuah runtut waktu (time series) memiliki beberapa pola. Pola-pola tersebut akan terlihat pada runtut waktu yang sudah digambarkan melalui grafik. Pola-pola tersebut dapat dijelaskan dengan banyaknya kemungkinan hubungan sebab akibat. Adapun pola-pola umum runtut waktu adalah sebagai berikut (Assuri, 2016)

\section{a. Pola Acak (Random)}

Pola yang muncul karena peristiwa yang tidak terduga seperti perang sehingga menghasilkan pola yang tidak beraturan.Seperti pada Gambar 1 pola acak, fluktuasi data berubah-ubah tidak dapat diprediksi. 


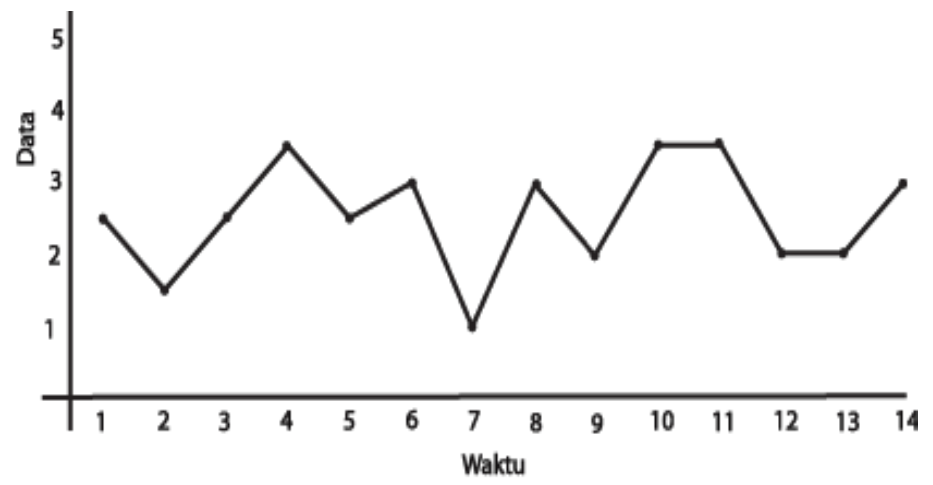

Gambar 1. Bentuk Umum Pola Acak

\section{b. Pola Musiman}

Pola musiman dihasilkan oleh kejadian yang terjadi secara musiman atau periodik contoh: iklim, hari besar keagamaan, kwartal waktu terntu. Seperti pada Gambar 2 terjadi peningkatan di periode 6,12, dan 18.

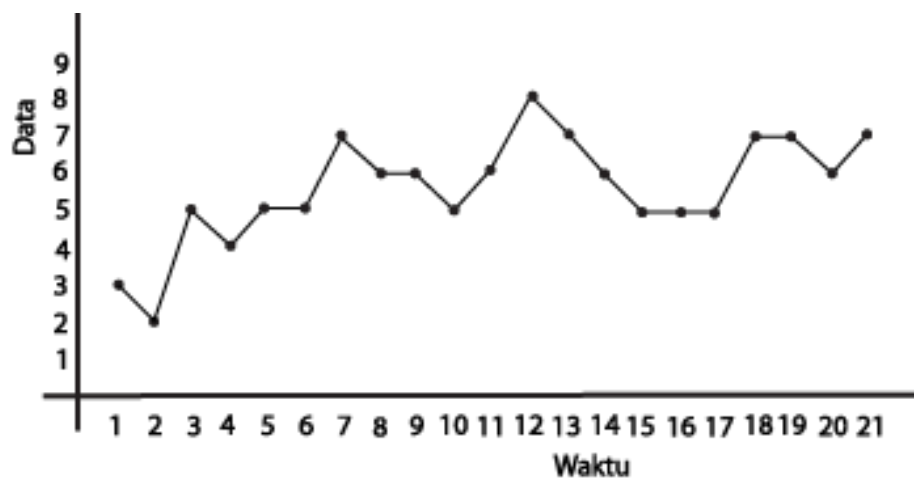

Gambar 2. Bentuk Umum Pola Musiman

\section{c. Pola Siklus}

Pola siklus adalah pola perubahan naik atau turun, sehingga siklus ini berubah dan bervariasi dari suatu siklus ke siklus berikutnya. Pola siklus dihasilkan oleh pengaruh ekspansi ekonomi. 


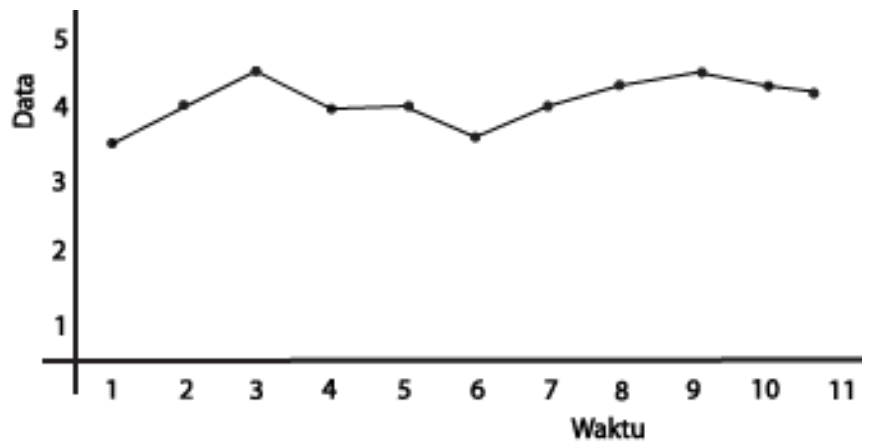

Gambar 3. Bentuk Umum Pola Siklus

\section{d. Pola Trend}

Pola trend disebabkan oleh perubahan jangka panjang yang terjadi di sekitar faktor-faktor yang mempengaruhi data runtut waktu (time series).Di dalam pola trend terjadi peningkatan atau penurunan selama beberapa periode tertentu.Seperti pada Gambar 4. pola data mempunyai kencenderungan meningkat.

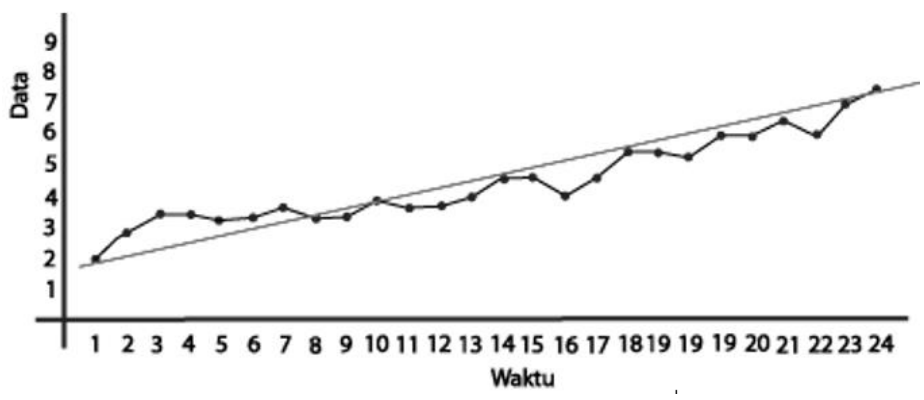

Gambar 4. Bentuk Umum Pola Trend

\subsection{Metode Exponential Smoothing}

Exponential Smoothing adalah suatu prosedur yang secara terus menerus memperbaiki peramalan dengan merata-rata nilai masa lalu dari suatu data runtut waktu dengan cara menurun (exponential). Macam-macam metode exponential smoothing yaitu (Makridakis, 2000)

\section{a. Single Exponential Smoothing}

Metode Single Exponential Smoothing menambahkan parameter alphadalam model untuk mengurangi faktor kerandoman. Nilai prediksi dapat dicari dengan menggunakan rumus berikut 


$$
\hat{\mathrm{Y}}_{\mathrm{t}+1}=\alpha \mathrm{Y}_{\mathrm{t}}+(1-\alpha) \hat{\mathrm{Y}}_{t}
$$

\section{b. Brown's Double Exponential Smoothing}

Metode single exponential smoothing hanya akan efektif apabila data time series yang diamati memiliki pola horizontal. Jika metode itu digunakan untuk data time series yang memiliki unsur trend yang konsisten, nilai-nilai perkiraan akan selalu berada di belakang nilai aktualnya. Metode ini dikembangkan oleh Brown's untuk mengatasi perbedaan yang muncul antara data aktual dan nilai peramalan apabila ada trend pada polanya. Persamaan yang digunakan pada metode ini adalah

$$
\begin{aligned}
& A_{t}=\alpha Y_{t}+(1-\alpha) A_{t-1} \\
& A_{t}^{\prime}=\alpha A_{t}+(1-\alpha) A_{t-1}^{\prime} \\
& a_{t}=2 A_{t}-A_{t}^{\prime} \\
& b_{t}=\frac{\alpha}{1-\alpha}\left(A_{t}-A_{t}^{\prime}\right)
\end{aligned}
$$

Persamaan yang digunakan untuk membuat peramalan pada periode $\mathrm{p}$ yang akan datang adalah:

$$
\hat{Y}_{t+p}=a_{t}+b_{t} p
$$

\subsection{Metode Analisis Data}

Metode analisa data adalah metode preprocessing atau metode mempersiapkan data agar data tersebut dapat sesuai dengan metode yang digunakan. Dalam penelitian ini analisa data yang digunakan adalah sebagai berikut

a. Membuat scatter plot atau diagram garis untuk mengetahui pola sebaran data

b. Melakukan uji stasioneritas dengan menggunakan uji akar unit

c. Melakukan transformasi logaritma natural jika data tidak stasioner.

d. Kemudian melakukan uji akar unit kembali 
e. Melakukan identifikasi model stasioner dengan menggunakan plot ACF dan PACF dari data yang sudah ditransformasikan. Kemudian memberikan kesimpulan dari model stasioner data tersebut.

f. Kemudian data dapat digunakan untuk metode eksponensial smoothing

\section{Hasil dan Pembahasan}

\subsection{Perancangan Model}

\section{a. Single Exponential Smoothing}

Metode Single Exponential Smoothing adalah metode ini digunakan untu peramalan jangka pendek. Model mengasumsikan bahwa data berfluktuasi di sekitar nilai mean yang tetap, tanpa trend atau pola pertumbuhan konsisten. Tidak seperti Moving Average, Exponential Smoothing memberikan penekanan yang lebih besar kepada time series saat ini melalui penggunaan sebuah konstanta smoothing (penghalus). Konstanta smoothing mungkin berkisar dari 0 ke 1 . Nilai yang dekat dengan 1 memberikan penekanan terbesar pada nilai saat ini sedangkan nilai yang dekat dengan 0 memberi penekanan pada titik data sebelumnya. Data yang digunakan dalam penelitian ini adalah data tinggi muka air bendungan wonogiri, pengamatan data harian rata-rata pada tahun 2018 sejumlah 213 data.

Tabel 1. Estimasi Parameter Single Exponential Smoothing (SES)

\begin{tabular}{ll}
\hline Parameters Alpha & 0.7940 \\
\hline Sum of Squared Residuals & 37.17410 \\
Root Mean Squared Error & 0.417763 \\
End of Period Levels Mean & 136.2094 \\
\hline
\end{tabular}

Berdasarkan Tabel 1, diperoleh estimasi parameter yang mengacu pada Persamaan (1) sebagai berikut

$$
\widehat{Y}_{t+1}=0.794 Y_{t}+(1-0.794) \hat{Y}_{t}
$$


b. Brown's Double Exponential Smoothing

Metode Brown's Double Exponential Smoothing adalah metode ini dikembangkan oleh Brown's untuk mengatasi perbedaan yang muncul antara data aktual dan nilai peramalan apabila ada trend pada poltnya. Dasar pemikiran dari pemulusan eksponensial linier dari Brown's adalah serupa dengan rata-rata bergerak linier (Linier Moving Average), karena kedua nilai pemulusan tunggal dan ganda ketinggalan dari data yang sebenarnya bilamana terdapat unsur trend, perbedaan antara nilai pemulusan tunggal dan ganda ditambahkan kepada nilai pemulusan dan disesuaikan untuk trend. Data yang digunakan dalam penelitian ini adalah data tinggi muka air bendungan wonogiri, pengamatan data harian rata-rata pada tahun 2016 sejumlah 213 data.

Tabel 2. Estimasi Parameter Brown's Double Exponential Smoothing

\begin{tabular}{ll}
\hline Parameters Alpha & 0.2680 \\
\hline Sum of Squared Residuals & 21.79573 \\
Root Mean Squared Error & 0.319887 \\
End of Period Levels Mean & 136.1449 \\
$\quad$ Trend & -0.013158 \\
\hline
\end{tabular}

Berdasarkan Tabel 2, diperoleh estimasi parameter yang mengacu pada Persamaan (2) dan Persamaan (3), sebagai berikut

$$
\begin{gathered}
A_{t}=0,268 Y_{t}+(1-0,268) A_{t-1} \\
A_{t}^{\prime}=0,268 A_{t}+(1-0,268) A_{t-1}^{\prime} \\
a_{t}=2 A_{t}-A_{t}^{\prime} \\
b_{t}=\frac{0,268}{1-0,268}\left(A_{t}-A_{t}^{\prime}\right) \\
\hat{Y}_{t+p}=a_{t}+b_{t} p
\end{gathered}
$$

Berdasarkan persamaan (4) dan persamaan (5) diperoleh hasil prediksi tinggi muka air sungai Bengawan Solo pada bendungan Wonogiri, seperti pada Gambar 1 


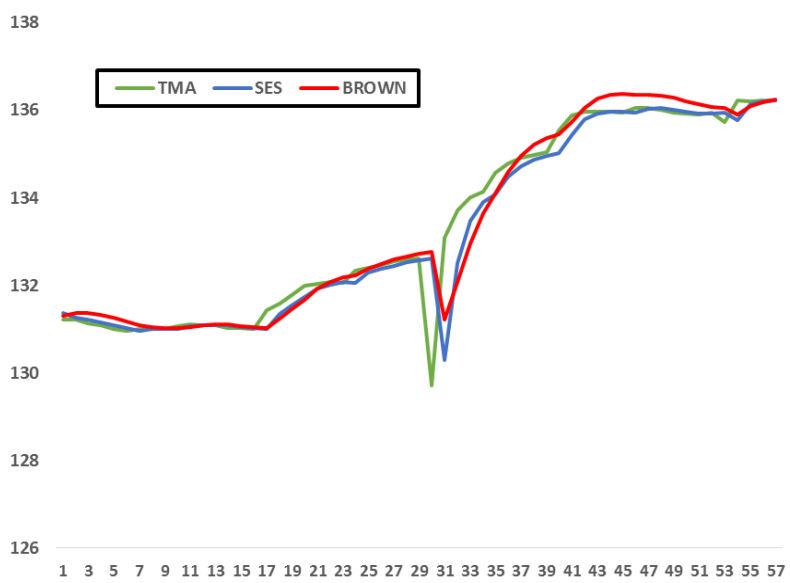

Gambar 5. Prediksi TMA dengan SES dan Brown's

\subsection{Perbandingan Model}

Perbandingan model dilakukan dengan cara membandingkan eror dari tiap model, baik Single Exponential Smoothing dan Brown's Double Exponential Smoothing.

Tabel 3. Validasi Model

\begin{tabular}{lll}
\hline Model & MSE & MAPE \\
\hline Single Exponential Smoothing (SES) & 0,174528 & 0,099209 \\
Brown's Double Exponential Smoothing & 0,102326 & 0,098495 \\
\hline
\end{tabular}

Berdasarkan Tabel 3, nilai MAPE untuk Single Exponential Smoothing sebesar 0,099209 yang artinya 9,992\% tingkat kesalahannya. Nilai MAPE untuk Brown's Double Exponential Smoothing sebesar 0,098495 yang artinya 9,8495\% tingkat kesalahannya. Perbandingan nilai MSE terlihat nilai terkecil adalah Brown's Double Exponential Smoothing, yang dapat berarti model yang cocok untuk data TMA pada pos pemantauan Wonogiri periode Juni - Desember 2018 adalah metode Brown's Double Exponential Smoothing.

\section{Simpulan}

Nilai MAPE untuk Brown's Double Exponential Smoothing sebesar 0,098495 yang artinya 9,8495\% tingkat kesalahannya. Perbandingan nilai MSE terlihat nilai terkecil adalah Brown's Double Exponential Smoothing, yang dapat berarti model yang cocok untuk data TMA pada pos pemantauan Wonogiri periode 
Juni - Desember 2018 adalah metode Brown's Double Exponential Smoothing. Berdasarkan penelitian yang sudah dilakukan maka saran yang diberikan kepada peneliti selanjutnya adalah data TMA pos Pemantauan Bendungan Wonogiri berpola stasioner sehingga dapat diselesaikan dengan metode stasioner lainnya seperti Autoregresif, Moving Average, dan ARIMA. Oleh karena itu diperlukan perancangan aplikasi untuk memprediksi TMA tersebut agar dapat langsung bermanfaat untuk deteksi bencana banjir di sekitarnya.

\section{Daftar Pustaka}

Anwar, B. (2011). Penerapan Algoritma Jaringan Saraf Tiruan Backpropagation dalam Prediksi Tingkat Suku Bunga Bank. Jurnal SAINTIKOM Vol 10 No 2, 111-123.

Asdak, C. (2010). Hidrologi dan Pengelolaan Daerah Aliran Sungai. Yogyakarta: Gadjah Mada University Press.

Bakhrun, A. (2013). Perbandingan Metode Adaline dan Backpropagation untuk Prediksi Jumlah Pencari Kerja di Jawa Barat. Bandung:Universitas Komputer Indonesia.

Broto, A. W. (2010). Perbandingan Aplikasi Jaringan Saraf Tiruan Backpropagation dengan ARCH-GARCH untuk memprediksi Indeks Harga Saham Gabungan . Semarang: Universitas Diponegoro.

Gunaryati, A. (2015). Perbandingan antara Metode Statistika dan Metode Neural Network pada Model Peramalan Indeks Harga Perdagangan Besar. Jurnal Teknologi dan Rekayasa Vol 2 No 1 , 23-35.

Kurniawati, O. T. (2016). Analisis Tinggi Muka Air Bengawan Solo Hilir Akibat Adanya Floodway dengan Metode Jaringan Saraf Tiruan. Malang: Universitas Brawijaya.

Mahmuda, A. F. (2012). Analisis Kuantitas dan Kualitas Air Sungai Pampang Kotamadya Makasar. Makasar: Universitas Hassanudin.

Ruminta. (2008). Model Temporal Curah Hujan dan Debit Sungai Citarum Berbasis ANFIS. Jurnal Sains Dirgantara Vol 6 No 1, 22-38.

Setiawan, A. (2013). Aplikasi Peramalan Penjualan Kosmetik dengan ARIMA. Surabaya: Universitas Kristen Petra. 
Suprayogi, H. (2015). Profil Pengelolaan Sumber Daya Air Wilayah Sungai Bengawan Solo. Surakarta: Dinas Pekerjaan Umum. 